\title{
Vielas de sentido: discurso e imaginário na cobertura d'O Globo sobre a "ocupação" do Alemão
}

\author{
Alleys of meaning: discourse and imaginary in O Globo's news coverage of the \\ "occupation" of the Alemão slum
}

\section{Cícero Costa Villela}

Doutorando em Ciências da Linguagem (PPGCL/Univás). Mestre em Comunicação e Identidades (PPGCom/UFJF). Membro do grupo de pesquisa "Sensus" e Professor Substituto da Faculdade de Comunicação da UFJF.

\section{Wedencley Alves Santana}

Professor do Programa de Pós-Graduação em Comunicação e Sociedade da UFJF. Doutor em Linguística pela UNICAMP. Coordenador do grupo de pesquisa Sensus-Comunicação e Discursos.

\section{Artigo submetido em 11 de Agosto de 2019 Artigo aceito em 28 de Outubro de 2019}

\section{RESUMO}

0 presente trabalho se insere no contexto de uma pesquisa que pretende fazer uma cartografia dos discursos sobre as favelas. Nesse sentido, a partir da perspectiva da Análise de Discurso, busca-se analisar matérias sobre o acontecimento discursivo em que se constituiu a chamada "pacificação do Alemão". Intenta-se compreender o papel do jornalismo na construção imaginária e simbólica do espaço urbano enquanto destituído de heterogeneidade. Para isso, recorre-se ao jornal $O$ Globo e ao arquivo de reportagens sobre o dia seguinte à ocupação do Complexo do Alemão. Parte-se do pressuposto de que, ao narrar o espaço urbano, a mídia também situa e contribui para a construção de sentidos e sujeitos passíveis de serem encontrados em determinados ambientes, mas que - hipótese central - é também marcada por uma certa heterogeneidade.

PALAVRAS-CHAVE: Comunicação; Análise do Discurso; Favelas Cariocas.

\section{ABSTRACT}

Dossiê Espaço Urbano e Imaginação Cultural - https://revistaecopos.eco.ufrj.br/ 
This paper is part of a research that aims to make a map of discourse on the slums. In this sense, from the perspective of Discourse Analysis, we intend to analyze stories about the discursive event known as "the pacification of Alemão slum". Our objective is to understand the role of journalism in the imaginary and symbolic construction of urban space as non-heterogeneous one. This study use $O$ Globo's files about the day after of occupation of Alemão. Thus, in narrating the urban space, the media also locates and contributes to the construction of subjects and meanings that can be found in certain environments, but - our main hypothesis - it is also marked by a certain heterogeneity.

KEYWORDS: Communication; Discourse Analysis; Slums.

\section{Pensar discursivamente a cidade}

Analisar a "Pacificação do Morro do Alemão"1 como "acontecimento discursivo" é, antes, partir da hipótese de que os sentidos produzidos até então por narrativas sobre a cidade sofreram, de alguma forma, deslocamentos relevantes, a ponto de percebermos alguma descontinuidade em relação aos discursos anteriores produzidos sobre o Rio de Janeiro. É também atentar para a possibilidade de transformações na relação simbólica dos moradores com a cidade. Para isso, faz-se necessário uma reflexão prévia sobre os mecanismos sociais de atribuição de sentidos para a cidade e seus lugares habitáveis e o lugar dos meios de comunicação neste processo. Isso porque, como afirma Mendonça (2010),

As cidades, como os discursos, estão longe de possuírem algo como uma essência concreta ou um sentido único. Como produtos de um processo complexo de apropriações simbólicas, tanto os espaços como os discursos são, por natureza, polissêmicos, e terão suas interpretações hegemônicas modificadas, gradualmente, em função das historicidades envolvidas no jogo de relações de poder que compõem a sociedade. (p. 2)

\footnotetext{
${ }^{1}$ Evento ocorrido em 2010, com a ocupação de um dos complexos de favela mais extensos na cidade do Rio de Janeiro por forças de segurança, tanto estaduais (Polícia Militar e Polícia Civil), quanto federais (Força de Segurança Nacional, com o apoio das Forças Armadas), com o propósito de, supostamente, desalojar os traficantes de drogas da região. Geralmente associados à violência e disputas intestinas, os "comandos" responsáveis pelo processamento e venda de drogas entram constantemente em confronto por conquistas de pontos e posições neste comércio. A estas disputas, as narrativas hegemônicas nomearam "guerra do tráfico", termo discursivamente relevante, até por não serem nomeadas justamente como "disputas" ou "conflitos". O substantivo "pacificação", portanto, já se estabelece como legitimação do nomeado, o marco semântico que funciona como sustentação discursiva de uma certa memória da cidade, de afetos presentes e ações futuras.
}

Dossiê Espaço Urbano e Imaginação Cultural - https://revistaecopos.eco.ufrj.br/

ISSN 2175-8689 - v. 22, n. 3, 2019

DOI: 10.29146/eco-pos.v22i3.27415 
Podemos dizer que o espaço urbano, materialidade das relações de poder e de sentidos, apesar de se pretender uno e homogêneo, não se constrói dessa maneira. 0 espaço urbano é composto por inúmeros espaços heterogêneos que marcam a desigualdade da sociedade por meio da divisão/distribuição/segregação espacial.

Michel de Certeau (1990), na sua reflexão sobre a vida cotidiana, parte de uma dicotomia que nos é útil para compreender a cidade enquanto espaço simbolizado e de relações de sentidos. Ele fala de estratégias e táticas para produzir um conceito de espaço e de cidade que servirá para descrever as microrresistências que os sujeitos oferecem em seu cotidiano.

\footnotetext{
Chamo de "estratégia" o cálculo das relações de força que se torna possível a partir do momento em que um sujeito de querer e poder é isolável de um "ambiente". Ela postula um lugar capaz de ser circunscrito como um próprio e, portanto, capaz de servir de base a uma gestão de suas relações com uma exterioridade distinta. (...) Denomino, ao contrário, "tática" um cálculo que não pode contar com um próprio, nem, portanto, com uma fronteira que distingue o outro como totalidade visível. A tática só tem por lugar o do outro. (De CERTEAU, 1990, p.45)
}

Para De Certeau, as práticas cotidianas - e, dentre elas, as práticas de espaço - são absorvidas por essas duas estruturas explicativas. Em relação à cidade, elas vão se comportar de duas formas distintas. Por um lado, as estratégias vão representar o discurso urbanista hegemônico que propõe determinada forma de fruição do espaço urbano que determina o lugar de cada sujeito e para que sirva cada um dos locais construídos no perímetro urbano. Ou seja, a estratégia é a organização, a governança que tenta disciplinar e controlar a população da cidade.

As táticas são as formas de se consumir o que é dado como pronto pelas estratégias. Ou seja, é por meio das táticas que os sujeitos se apropriam das estruturas que são dadas e as ressignificam, dando a elas novos usos ou novos trajetos. A partir desses dois operadores básicos, De Certeau vai definir o que é a cidade, o espaço e os lugares.

Segundo o autor, a cidade, definida pelas estratégias do urbanismo, possui três características básicas: 1 - Ela produz um espaço próprio; 2 - estabelece um sistema sincrônico para substituir as resistências das tradições; e 3 - Cria um sujeito universal e

\section{Dossiê Espaço Urbano e Imaginação Cultural - https://revistaecopos.eco.ufrj.br/ \\ ISSN 2175-8689 - v. 22, n. 3, 2019 \\ DOI: 10.29146/eco-pos.v22i3.27415}


anônimo que é a própria cidade (De CERTEAU, 1990. p.160). Definida dessa forma, o que há é a vontade de tornar homogêneo o espaço urbano, com o apagamento das diferenças de sentido que emergem da própria vivência dos sujeitos da cidade. A estratégia, no entanto, sempre tende ao fracasso, diante do próprio movimento tático dos sujeitos urbanos - a cidade é heterogênea, polissêmica e contraditória.

A linguagem do poder "se urbaniza", mas a cidade se vê entregue a movimentos contraditórios que se compensam e se combinam fora do poder panóptico. A Cidade se torna o tema dominante dos legendários políticos, mas não é mais um campo de operações programadas e controladas. Sob os discursos que a ideologizam, proliferam as astúcias e as combinações de poderes sem identidade, legível, sem tomadas apreensíveis, sem transparência racional - impossíveis de gerir. (De CERTEAU, 1990, p. 161)

Esses movimentos contraditórios que De Certeau observa na cidade são reafirmados, embora a partir de um outro olhar conceitual, por Massey (2005), que estende essa reflexão atenta ao heterogêneo para o espaço - seja ele a cidade ou os lugares globais - como um todo:

É mais fácil começar reduzindo-a a algumas proposições. Elas são as seguintes. Primeiro, reconhecemos o espaço como o produto de interrelações, como sendo construído através de interações, desde a imensidão global até o intimamente pequeno. (...) Segundo, compreendemos o espaço como a esfera da possibilidade da existência da multiplicidade, no sentido da pluralidade contemporânea, como a esfera na qual distintas trajetórias coexistem; como a esfera, portanto, da coexistência da heterogeneidade. Sem espaço, não há multiplicidade; sem multiplicidade, não há espaço. Se espaço é, sem dúvida, o produto de interrelações, então deve estar baseado na existência da pluralidade. Multiplicidade e espaço são co-constitutivos. Terceiro, reconhecemos o espaço como estando sempre em construção. Precisamente porque o espaço, nesta interpretação, é um produto de relaçõesentre, relações que estão necessariamente embutidas em práticas materiais que devem ser efetivadas; ele está sempre no processo de fazer-se. Jamais está acabado, nunca está fechado. Talvez pudéssemos imaginar o espaço como uma simultaneidade de estórias-atéagora. (MASSEY, 2005, p. 29)

Massey retira do espaço sua condição de objeto estático. Para ela, o espaço, e no nosso caso o espaço urbano, é altamente dinâmico, exatamente por ser a materialidade das interrelações que se dão nele e por ele. Construí-lo é também produzir os sujeitos, olhá-lo é perceber a possibilidade infinita de encontros e de trajetórias.

A construção simbólica da cidade é objeto de disputas constantes, onde determinadas instituições, como Estado e Mídia, agem sob a vontade de poder torná-lo legível, de produzir uma narrativa única que dê conta da multiplicidade com a qual se 
apresenta a cidade. Mas a produção dos sentidos no/para o espaço urbano se modifica de acordo com diferentes condições de produção, e por conta mesmo desta "abertura", esta incompletude de um espaço por se fazer, o que produz contínuos (ainda que ínfimos) deslizamentos de sentidos, metaforizações dos sujeitos².

Ora, a percepção da cidade como espaço múltiplo e marcado pela incompletude não nos pode fazer descuidar do fato de que há, sim, instâncias de contenção da polissemia. $\mathrm{Ou}$, como afirma Orlandi:

Não é porque o processo de significação é aberto que ele não é regido, administrado. Ao contrário, é justamente lá onde a língua, passível de jogo (ou afetada pelo equívoco), se inscreve na história para que haja sentido, é que fazemos face à questão da determinação. (ORLANDI, 2004, p. 19)

Massey (2005) também reconhece as geometrias do poder, que produzem exatamente uma verticalização das relações sociais da cidade, fazendo com que a interação igualitária se perca e exista sobredeterminação de alguns grupos sobre outros. Discursivamente, Orlandi também falará de uma "sobredeterminação do urbano à cidade", sendo o "urbano" o espaço gerido:

\begin{abstract}
Temos proposto, em nossa reflexão, uma relação entre ordem, que é do domínio do simbólico na relação com o real da história (a sistematicidade sujeita a equívoco), articulação necessária e contraditória entre estrutura e acontecimento, enquanto a organização refere ao empírico e ao imaginário (o arranjo das unidades). Nossa finalidade é assim ultrapassar a organização do discurso urbano para atingir a compreensão da ordem do discurso urbano, isto é, procurar entender como o simbólico, confrontando-se com o político, configura sentidos para/na cidade e não fica apenas na organização do discurso urbano que nos relega ao imaginário, às ilusões (eficazes) da urbanidade (ORLANDI, 2004, p. 35).
\end{abstract}

O que a autora vai fazer é olhar a cidade como uma textualidade prenhe de sentidos; daí o recurso à dualidade conceitual entre "organização textual" e "ordem discursiva", dispositivos analíticos próprios para a análise de textualidades outras. Com isso, a cidade estará franqueada para um olhar discursivo, capaz de percebê-las em suas contraditórias relações de sentido, repetição e deslocamento, paráfrase e polissemia, desejo de ordem e

2 Em nossa perspectiva discursiva, sujeito e sentido constituem-se, e por isso se "deslocam", concomitantemente (ver ORLANDI, 2004). Ainda nesta perspectiva, metáfora é um fenômeno semântico de produção de sentido, e que se constitui como transferência, mudança.

Dossiê Espaço Urbano e Imaginação Cultural - https://revistaecopos.eco.ufrj.br/ 
mudança. A ênfase, neste momento, no entanto, é a do fechamento do sentido, relações de poder que devem ser compreendidas:

A sobredeterminação que referimos mais acima, vista nessa perspectiva de ordem do discurso, produz, além disso, como um seu efeito a verticalização das relações horizontais da cidade, que, de espaço material contíguo, se transforma em espaço social hierarquizado (vertical). Nesse processo de verticalização, o "socius" (o aliado) e "hostis" (o inimigo) se indistinguem e a cidade passa a ser "urbanizada" num movimento em que as diferenças, verticalizadas, se significam pela remissão categórica a níveis de dominação e impede a convivência, o trânsito horizontal, as relações de contiguidade. A organização social vai refletir essa verticalidade da formação social urbana no espaço horizontal, separando regiões, determinando fronteiras que nem sempre são da ordem do visível concreto, mas funcional no imaginário sensível. Segregação. (ORLANDI, 2004, p. 35)

Orlandi nos induz a perceber a hierarquização das relações sociais na cidade e pretende ultrapassar o imaginário que segrega (urbano) para atingir o funcionamento do real do discurso na fala cotidiana (cidade). E, por indução, trazemos a mídia para nossa reflexão, ao vê-la como reprodutora do discurso do urbano, como se torna uma instância para a compreensão do imaginário urbano moderno.

Dados esses conceitos e a produção simbólica da cidade e da segregação a partir do registro da urbanidade, passemos então à discussão do papel da mídia na produção/reprodução do imaginário urbano e como ela materializa essas relações de poder que produzem territórios e sujeitos na cidade.

\section{Mídia e a produção do imaginário urbano}

$\mathrm{Na}$ perspectiva analítico-discursiva, um conceito operativo é o de imaginário, o mecanismo ideológico de naturalização de sentidos. As ilusões constitutivas são exemplos desse registro, como aquela com que o sujeito se acredita origem do dizer, e a outra, que atribui ao discurso efeitos de evidência. Mas é preciso não confundir "ilusões constitutivas" - portanto, necessárias à realização discursiva, qualquer que seja - com engodo, engano ou ficção. A análise do discurso não parte de uma epistemologia realista, em que haveria que se suspender o véu da ideologia para atingir a verdade. 0 propósito é compreender o funcionamento dos discursos, e isso leva o analista a se defrontar necessariamente com o imaginário, reconhecer seu papel no jogo dos sentidos. 
Como dissemos, não há relação direta entre mundo e linguagem, entre palavra e coisa. A relação não é direta, mas funciona como se fosse, por causa do imaginário. Ou, como diz Sercovich (1977), a dimensão imaginária de um discurso é sua capacidade para a remissão de forma direta à realidade. Daí seu efeito de evidência, sua ilusão referencial. Por outro lado, a transformação do signo em imagem resulta justamente da perda de seu significado, ou seja, do seu apagamento enquanto unidade cultural ou histórica, o que produz sua "transparência". Dito de outra forma: se se tira a história, a palavra vira imagem pura. Essa relação com a história mostra a eficácia do imaginário, capaz de determinar transformações nas relações sociais e de construir práticas. No entanto, em seu funcionamento ideológico, as palavras se apresentam em sua transparência (...) (ORLANDI, 2007, p. 32)

Discursivamente, referir-se ao imaginário urbano, portanto, é admitir que, se a cidade é heterogênea, passível de ser relatada por narrativas múltiplas, suscetível de ser interpretada ou submetida a uma infinidade de leituras possíveis, ela também é um espaço onde alguns sentidos tornam-se dominantes, naturalizados, e que isso tem a ver com relações de forças sociais, com a história.

Há algum tempo, a construção do imaginário urbano - a fixação de sentidos sobre a cidade - e seus sujeitos passa pela agência dos meios de comunicação, principalmente os hegemônicos. Evidentemente, não são as únicas instâncias a contribuir para a "naturalização" de alguns sentidos de cidade e seus sujeitos em detrimentos de outros. As relações comunitárias, as vivências práticas, a ordem administrativa, a esfera dos negócios, o imaginário estético-literário e artístico, tudo isso constitui, como uma rede complexa e muitas vezes multiforme, aquilo que o cidadão compreenderá de sua cidade.

Mas não é demasiado dizer que os meios de comunicação tradicionais - e hoje, de forma cada vez mais premente, as redes - desempenham um lugar central na produçãoreprodução-deslocamento de discursos e sentidos sobre o que é a cidade. Podemos mesmo dizer - e essa é uma hipótese que aventamos - que a mídia funciona como um mapa de leitura da cidade. Dessa forma, ela se dá o estatuto simbólico na definição dos ambientes.

Apesar de não analisar a mídia de forma direta, a proposta do semanticista Eduardo Guimarães (a de leitura dos mapas de cidade) é de utilidade para entendermos o funcionamento da mídia como um guia socialmente relevante: "o sentido do mapa não se dá como descrição de uma cidade, nem como narração de sua história, ele se dá, diríamos, no sempre depois de seu presente, como instrução semântica” (2002 p.60).

Assim como um mapa, a mídia é uma instrução semântica da cidade, ao produzir relatos sobre o espaço urbano. As narrativas midiáticas inserem os locais em relações 
simbólicas, tornando o espaço urbano pleno de sentidos. Ora, o relato tem papel fundamental na transformação da realidade existente: para o historiador Michel de Certeau, os relatos "transformam lugares em espaços ou espaços em lugares. Organizam também os jogos das relações mutáveis que uns mantêm com os outros" (1990 p. 203).

Nas mídias, o jornalismo - mais que o entretenimento e a publicidade ${ }^{3}$ - é a prática discursiva que funciona como um espaço privilegiado de "produção de verdades", e que se arroga a posição de relato suficiente da realidade.

Por isso, a narrativa da mídia sobre as favelas tende a buscar uma transparência, a fechar os sentidos, a silenciar discursos outros que tentam representar de forma alternativa o espaço urbano. Isso evidencia que o discurso é objeto de tensões e de lutas. Vale a pena recorrer a Foucault, quando o autor afirma que:

Em uma sociedade como a nossa, mas no fundo em qualquer sociedade, existem relações de poder múltiplas que atravessam, caracterizam e constituem o corpo social e que estas relações de poder não podem se dissociar, se estabelecer nem funcionar sem uma produção, uma acumulação, uma circulação um funcionamento do discurso. Não há possibilidade de exercício do poder sem certa economia dos discursos de verdade que funcione dentro e a partir desta dupla exigência. Somos submetidos pelo poder à produção da verdade. Isto vale para qualquer sociedade, mas creio que na nossa as relações entre poder, direito e verdade se organizam de uma maneira especial (FOUCAULT, 2008, p. 179-180)

Dentro dessa economia dos discursos, os meios de comunicação - e, com destaque, o jornalismo - se tornaram, há tempos, centrais em nossa vida cotidiana. Dado seu alcance, pode-se dizer que as mídias funcionam como arena pública, mesmo que dificilmente sejam vistos, para um grande público, como atores políticos interessados nesta arena. Em suma, o jornalismo acaba se convertendo em "lugar autorizado da produção e circulação da "verdade" - o que contribui para a sedimentação de algumas representações “oficiais” da cidade." (MENDONÇA, 2010, p. 5).

Se, recorrendo à $\mathrm{AD}$, compreendemos a instituição como espaço de estabilização de sentidos, pode-se afirmar que o jornalismo deve ser considerado uma prática discursiva

\footnotetext{
${ }^{3}$ Não desprezamos o papel do entretenimento e da publicidade como práticas que também de alguma forma constituem "discursos de verdade", mas estes, geralmente, funcionam por outros meios que não (ou, pelo menos, não frequentemente) relatos com pretensão totalizadora do que seja a realidade. Esta vocação totalizadora do jornalismo é o que sustenta o efeito - imaginário, lógico - de completude que lhe é próprio.
} 
institucionalizada, porque é capaz de estabelecer, embora atravessado por diferentes discursos, afetado por outras instituições e tensionado pelo próprio público, sentidos dominantes do que seja a cidade - ou o país ou o mundo - e a vida cotidiana. Como afirma Muniz Sodré (2009):

\begin{abstract}
Embora o relato jornalístico seja realmente uma "construção", feita por uma subjetividade a partir de outros relatos (provindos de fontes), existe uma presunção de imparcialidade, garantida pelo estatuto profissional do jornalista. Produz-se a notícia com a presunção de que o acontecimento adquira o estatuto pleno de fato, dando sentido ao que ocorreu e possibilidades de previsão quanto ao que ainda vai ocorrer. 0 poder do jornalismo, por mais frágil que possa parecer frente ao Estado e por menos que esconda a subjetividade do jornalista no embate hegemônico, consiste em sua exposição do fato social, ou seja, de uma unidade onde se entrecruzam outras táticas de poder típicas da sociedade civil em sua luta pela hegemonia das representações (p. 41).
\end{abstract}

A própria tese "informacional" do jornalismo vem demonstrar como é poderoso este lugar ocupado por ele na sociedade contemporânea. A crença de que haveria uma oposição de fundo entre informação e interpretação, sustentada pelas ideologias práticas dos profissionais de mídia e mesmo por alguns setores da academia, é antes uma espécie de legitimação deste poderoso efeito de transparência - sustentada retoricamente pela tal "objetividade" - produzido pelo jornalismo, e, por isso mesmo, política.

Ora, do ponto de vista discursivo, a interpretação é sempre política; está sempre permeada de relações de poder, e pode ser definida como a própria textualização do político. 0 jornalismo, ao apontar para o mundo, apaga a historicidade de sua construção e, ao mesmo tempo, produz os sujeitos que são referentes em sua narrativa. A mídia coloca em circulação as interpretações de uma forma específica, normalmente regidas pela sua própria lógica produtiva.

\title{
Estratégias analíticas
}

Primeiramente, algumas palavras sobre a estratégia analítica adotada neste estudo. Na medida em que uma textualidade - texto verbal, escrito ou falado, imagem, materialidades diversas - carrega um duplo estatuto, isto é, o de arranjo provisório da formulação de sentidos, uma "fotografia" dos processos discursivos que são contínuos na história, e, ao mesmo tempo, o acontecimento da própria discursividade (aliás, sua 
condição mesma de possibilidade), cumpre observar que é ela o locus privilegiado da observação dos sentidos.

Um postulado da AD é de que a ideologia - as relações de poder - se materializa no discurso e o discurso na língua (diremos linguagem) em sua realização, a textualidade. Portanto, o trabalho do analista se dá a partir da textualidade, mais propriamente sobre a base material do acontecimento discursivo. E este trabalho pode se dar segundo diversas estratégias analíticas. Cumpre esclarecer, assim, qual a utilizada neste estudo, que é, de certa forma, a mais ortodoxa.

Primeiramente, apesar de compreender que o jornal é composto de uma materialidade múltipla, para este trabalho, e pelo espaço exíguo de sua realização, optamos por efetuar uma análise eminentemente do verbal. Ela se dará a partir do desmembramento do texto em sequências discursivas, primeiro procedimento para ultrapassar os efeitos imaginários de completude e univocidade do texto.

Falamos de efeito imaginário porque a (a) intertextualidade e a (b) heterogeneidade são constitutivas da textualidade. No primeiro caso, porque um texto qualquer texto - estará necessariamente inserido numa relação de antecipação ou resposta a outros textos. No segundo, porque um texto é propriamente a materialização de, no mínimo, dois sentidos: aquele que é afirmado, e aquele que, dada a afirmação, é excluído, negado, relativizado etc.

Ao efetuar o desmembramento dos textos em SDs, a análise evidencia, por comparação e contraste, a multiplicidade de sentidos, por vezes contraditórios, num mesmo texto, e a relação extrínseca de cada enunciado no texto com outros enunciados em outros textos. Por enunciado, compreendemos a composição de sentidos, sobre base significante.

Será vista como enunciado, portanto, a sequência discursiva já compreendida em certa formação discursiva - a matriz de sentidos, que funciona como lugar de interpretação dos acontecimentos e dos processos históricos, lugar este que funciona como posição e condição de fala e de significação para os sujeitos que com ela se identificam ${ }^{4}$.

4 Para definições mais canônicas de formação discursiva ver Orlandi: "uma formação discursiva se define como aquilo que em uma formação ideológica dada - ou seja, a partir de uma posição dada em uma conjuntura dada - determina o que pode e deve ser dito" (2009, p. 43).

Dossiê Espaço Urbano e Imaginação Cultural - https://revistaecopos.eco.ufrj.br/ 
O desmembramento, ou dessegmentação, permitirá, assim, a comparação com outros enunciados em outros textos, e esta comparação fará emergir regularidades enunciativas que, por sua vez, poderão compor uma ou mais formações discursivas. $\mathrm{Ou}$ seja, farão parte de uma mesma ou de uma diferente matriz de sentidos e/ou lugar de interpretação. Chamamos a estas regularidades enunciativas de famílias de paráfrases, que devem ser entendidas aqui discursivamente. Paráfrase em $\mathrm{AD}$ diz respeito ao funcionamento da linguagem, e ocorre em oposição à polissemia, variância de sentido:

Os processos parafrásticos são aqueles pelos quais em todo dizer há sempre algo que se mantém, isto é, o dizível, a memória. A paráfrase representa assim o retorno aos mesmos espaços do dizer. Produzem-se diferentes formulações do mesmo dizer sedimentado. A paráfrase está do lado da estabilização. Ao passo que, na polissemia, o que temos é o deslocamento, ruptura dos processos de significação. Ela joga com o equívoco. (ORLANDI, 2005, p. 36).

É justamente o deslocamento dos processos de significação que serão observados num segundo momento, durante análise e comparação dos enunciados numa mesma família de paráfrase. A ocorrência de deslocamentos mais severos, já no caminho de uma ruptura, será o índice de que estaremos diante de uma outra formação discursiva. A estes deslocamentos, a AD denomina "processo metafórico". Só é possível, portanto, chegar a compreender a paráfrase - o efeito de mesmidade - e a polissemia - o efeito de diferença - por meio da análise, de contrastes e comparações, a partir de uma base material bem definida - daí a importância primordial do recorte e da questão discursiva, que funciona como o ponto de partida ou mesmo a razão de ser da análise.

Os recortes podem ser temáticos, espaciais ou temporais. Assim, nosso objeto empírico é a cobertura d'O Globo - o tradicional veículo jornalístico do Rio de Janeiro e possivelmente o único jornal considerado um quality paper na cidade, mas que tem relevância nacional - durante o evento da ocupação do Complexo do Alemão, um conglomerado de favelas situado na região conhecida como Zona da Leopoldina, o que seria a zona leste da cidade. Este acontecimento dado na história foi significado como a "Pacificação do Alemão", o que já faz emergir os sentidos de "intervenção sobre um estado de guerra preexistente".

Com relação à temporalidade da análise, sugerimos uma tripla tipologia: episódica, configuracional e longitudinal. Este estudo é sobre um episódio - A Pacificação do Alemão 
-, mas se trata de um desdobramento de pesquisa de mestrado na Faculdade de Comunicação Social da Universidade Federal de Juiz de Fora. A pesquisa em questão optou pela abordagem longitudinal, sobre os sentidos de favela n'O Globo ao longo de um período de 30 anos. Já as pesquisas configuracionais são eminentemente sincrônicas.

A dialética observada a partir da repetição e deslocamento dos sentidos faz parte da relação de forças na história. Os meios de comunicação, principalmente, os veículos hegemônicos na sociedade, buscam impor sentidos únicos acerca de acontecimentos, com consequente apagamento de outros sentidos possíveis. Embora esta dinâmica seja própria a todo e qualquer sujeito, não é difícil conceber que os atores sociais têm pesos diversos no estabelecimento de regularidades e rupturas de sentidos, embora, evidentemente, isto não implique em qualquer determinismo, pelo próprio fato da relação dinâmica e dialógica entre estes atores, por um jogo de força e contra-força, por uma disputa contínua de posições e hegemonias discursivas.

\section{Complexos sentidos}

Vejamos a primeira série de enunciados, compreendidos a partir de sequências coletadas da matéria "Incerteza dá lugar à esperança" ( $O$ Globo, p. 19, 05/12/2010), levando em consideração que, antes da intervenção no Complexo do Alemão, as narrativas dominantes reafirmavam o sentido de guerra para a disputa pelos pontos de processamento e venda de drogas entre comandos rivais. A sequência coletada traz para nós exatamente esse ponto de virada, essa ruptura, esse acontecimento midiáticodiscursivo, que aponta para um novo funcionamento das narrativas sobre a cidade.

E1 - Incerteza dá lugar à esperança: Livres dos traficantes, moradores do Alemão retomam suas vidas.

E2 - A brincadeira de X., de 8 anos, agora não tem mais hora pra acabar. Antes da ocupação do Complexo do Alemão, há uma semana, a mãe do menino, aluno da primeira série, obrigava-o a se recolher antes das $21 \mathrm{~h}$.

E3 - Depois da retomada do morro, as ruas passaram a ficar apinhadas de gente, principalmente crianças, que não correm mais o perigo de serem atropeladas pelas motos dos bandidos.

E4 - Para os mais velhos, a sensação é de que "o ar está mais leve", avalia Vanilda Pereira, moradora há 30 anos da região: - 0 ar mudou, sem dúvida. Eram muitos bandidos armados. Eles nunca fizeram nada conosco, mas era triste ver as crianças assistirem cenas como essas.

Dossiê Espaço Urbano e Imaginação Cultural - https://revistaecopos.eco.ufrj.br/ 
E5 - Mas é na hora de dormir no Complexo do Alemão, enquanto as buscas aos bandidos não terminam, que os nervos ficam à flor da pele. A sensação é de que, a qualquer momento, alguém vai invadir a sua casa, seja um policial para fazer revistas ou um bandido querendo usá-la como esconderijo, tomando-o como refém. E6 - Desde que o morro foi tomado, há uma semana, o sentimento do morador é um só: o de dormir de um olho no inimigo ou, como se diz na linguagem do morro, de olho no "alemão".

E7 - Além do medo de ter seu direito à inviolabilidade do lar quebrado, o morador convive com outro receio: o de que o estado o abandone mais uma vez. Neste caso, os fantasmas serão o retorno dos bandidos e a tomada da favela por milicianos.

E8 - Mas a esperança em um futuro melhor acaba sendo mais forte. (...) Até moradores, vítimas da violência do confronto entre bandidos e polícia, parecem não se importar com os prejuízos causados pela guerra do último domingo.

E9 - O passado só incomoda quem perdeu entes queridos na guerra do tráfico, como a catadora de lixo Maria das Dores Vieira (...): "Podem melhorar a favela, mas ainda guardo muita tristeza daqui. Perdi meu neto de 16 anos para o tráfico. Arrancaram um pedaço de mim".

E10 - Depois de sentir como os moradores do Alemão vivem, a equipe do Globo resolveu refazer a via crucis de Tim Lopes, quando ele foi levado para o alto daquele morro. 0 ambiente era pesado, mas ao lado do local onde foi encontrada a ossada do jornalista foi construído um campo de futebol, onde mais uma vez, havia crianças brincando. Os ares da favela, realmente, começaram a mudar.

Este bloco de enunciados se situa na narração dos acontecimentos que vieram logo depois da "pacificação" do Alemão. Ao descrever a comunidade após a ocupação das forças policiais, $O$ Globo procura traçar o que virá agora que eles estão "livres dos traficantes" (E1). Conforme o título da matéria, o tom das palavras de $O$ Globo é o da esperança que vai vencendo a incerteza.

Descritores como "mudança de ares", "leveza", "alegria”, enfim, a remissão a um cotidiano que se tornou menos opressor, dão o tom de uma nova narrativa do jornal. As falas dos moradores servem para construir esse sentido, de que após a "guerra" vem a esperança. Agora que os traficantes foram expulsos, não há mais uma ordem de medo, a favela foi integrada ao "Poder Público" - ao menos é esse efeito de sentido que vem se construindo. Os enunciados E2, E3 e E4 fazem um diálogo direto com a FD da guerra. Reafirmam seu efeito de verdade, de modo retrospectivo. Só houve pacificação porque havia guerra. A formação discursiva da guerra incide e sustenta a textualidade presente d'O Globo, mesmo que o objeto de discurso daquela formação aparentemente tenha sido extinto.

O discurso da pacificação, portanto, encontra sua razão de ser sob o signo da superação do objeto de discurso - "não há mais guerra" - que sustentava a FD Dossiê Espaço Urbano e Imaginação Cultural - https://revistaecopos.eco.ufrj.br/ 
hegemônica na cidade. Contraditoriamente, é sobre a ausência da guerra que a mesma FD se reafirma, sustentando a possível metaforização dos sentidos da cidade. Por isso, descrever o cotidiano agora sem guerra é tentar mostrar o antigo para elogiar o presente. As crianças podem brincar até tarde na rua (E2), as pessoas agora saem na rua sem medo (E3), a favela perdeu seu ar carregado, está com um ar mais leve.

Ainda há, porém, receios, e E5, E6 e E7 atestam esse fato. Os moradores ainda sentem dificuldade de dormir, faz-se presente o medo das batidas policiais e aqui se deixa entrever, levemente, o discurso da aversão e da desconfiança em relação à polícia. 0 jornal, no entanto, apara o contraditório e atua em sua função-autor, que, discursivamente, é a função, assumida pelo sujeito de discurso, de produção de coerência. Assim, E8 vai retornar à narrativa sobre uma nova realidade vivida pelos moradores, apesar das frestas de sentido abertas pelos próprios moradores.

Em E8 a esperança vence de vez a desconfiança e os sentidos de leveza retornam. E9 aparece para corroborar o fato de que o passado era realmente tenebroso na favela e que muitas foram as vítimas do tráfico. Mas é em E10 que $O$ Globo se mostra como personagem da cidade, afetado pela "guerra". Ao visitar o local onde Tim Lopes foi assassinado, os jornalistas descrevem poeticamente uma cena de crianças brincando. 0 local que antes era um descampado em que havia torturas e assassinatos pelos líderes do tráfico agora tem risos e crianças, o que faz os ares da favela mudarem.

Esses enunciados nos trazem questões interessantes. Pois, nesse momento, ainda não é possível perceber deslocamentos profundos nas formações discursivas. Há obviamente um discurso de reação, o processo de produção de discursos comparativos é reativo. A mudança de ares da favela aponta para uma abertura de sentidos, uma possível mudança no modo de significar a cidade e a favela - não mais marcada pela guerra, violência e tráfico.

O aparecimento dos moradores é domado pela orquestração de vozes produzidas pelos jornalistas. 0 que podemos identificar é, ao que parece, uma FD que retoma alguns aspectos românticos como a vida comunitária e o convívio mais próximo entre as pessoas. Mas que ainda assim apontam para a favela como uma realidade diferente da cidade, mantendo assim a clivagem simbólica entre "morro" e "asfalto". 
Narrar a favela dessa forma coloca $O$ Globo na perspectiva que sempre esteve quando descreveu a guerra contra os traficantes, ou seja, ao lado das forças da ordem ou o "Poder Público". Mostrar o antes e o depois da pacificação em termos de mudança de ares e leveza, é apresentar um cotidiano da favela como novidade. Narrar o comum passa a ser um jogo político de apropriação dos sentidos. Falar em jogos de futebol, cotidiano comum de qualquer comunidade, passa a ser um elemento comparativo com o que se dava anteriormente.

Logo, podemos dizer que descrever a favela a partir da FD da guerra era uma polícia do silêncio (ORLANDI, 2007), que silenciava o real da favela para poder descrever tudo como uma grande dominação que levava a todos a serem reféns em seu próprio território. Por isso, tirar o cotidiano real dos moradores do silêncio aparece como novidade em $O$ Globo.

E11 - 0 terror e o alívio de quem convivia com o tráfico: "Eu ouvia gritos a noite toda. Escutava as pauladas", contam moradores que hoje se sentem libertados.

E12 - Criado desde os 10 anos no Complexo do Alemão, ele se acostumou ao barulho de tiros e gritos das vítimas do tráfico. A primeira noite livre dos bandidos foi comemorada, mas, ao contrário de $\mathrm{X}$, muitos dos que moram no conjunto de favelas do Alemão e da Vila Cruzeiro, ainda desconfiados, preferem esperar pra crer.

E13 - "Agora posso falar porque sei que a polícia veio pra ficar. A operação foi rápida e não fez vítimas inocentes, bem diferente das outras.

E14 - Morador do alto da favela da Grota: "Eu ouvia gritos a noite toda. Quando eles não queriam barulho, colocavam uma bola de pingue-pongue na boca da vítima para ela não gritar. Escutava as pauladas, até mesmo com pedaço de tijolo, na cabeça da vítima. De manhã, quando acordava, sentia o cheiro de sangue".

E15 - "Espero que a polícia fique aqui mesmo. Parece que estou passando por um processo de libertação".

E16 - Agora, olhos e sorrisos bem abertos: Planos para o futuro substituem o medo que imperou até ocupação.

E17 - Moradora da Favela Nova Brasília há 37 anos, Eliane conta que evitava olhar para os bandidos: - As ruas eram muito agitadas. Saía de casa porque não tinha outro jeito. Agora está bem melhor. Desta vez eles ficam - disse, referindo-se à ocupação policial.

E18 - "Antes, eu dizia que morava na Nova Brasília e não gostava quando falavam que era no Alemão. No domingo, logo depois da ocupação, já passei a dizer que moro no complexo.

E19 - Questionada sobre as cenas de terror que foi obrigada a assistir, a moradora resumiu uma atitude coletiva de anos de domínio do tráfico: - A gente tinha que fechar os olhos e a boca, e rezar. 
Esse bloco de análise, retirado da matéria "O terror e o alívio de quem convivia com o tráfico" (O Globo, p. 32, 05/12/2010), não se diferencia de maneira muito profunda do que descrevemos anteriormente. 0 único ponto em que eles se afastam é a estratégia de formulação. Se um procura os sentidos de leveza e de esperança, buscando mais o presente e o futuro da comunidade; estes procuram traçar também uma fala de esperança de mudança, mas olhando para o passado.

Ao descrever o passado, $O$ Globo retorna às regiões da FD da Guerra para mostrar o "cotidiano violento" e as estratégias de dominação utilizadas pelos agentes do "Poder Paralelo". O processo de produção de sentidos das favelas está em aberto, mas ainda se mantém uma concepção de separação da cidade. A favela está se integrando à ordem da cidade, mas ainda é uma realidade cultural e social de outra instância.

Esse bloco, no entanto, traz algo que parece pôr o discurso d'O Globo em momentânea crise. Emerge o contraditório, falha o sentido único. O que se vinha construindo era a imagem de uma ocupação da favela como um evento sem violência, nem mortes. Se olharmos as páginas do jornal, não encontramos quaisquer relatos que remetam a isso. Contudo, a descrição feita da ocupação por um morador vai fazer falhar, nem que seja por instantes, o sentido de uma nova realidade.

Em E13 o morador se refere à certeza de que a polícia "veio para ficar" e de que "não morreu ninguém inocente". Discursivamente, há uma equivocidade neste enunciado, que aponta para duas reformulações possíveis: uma no sentido de atestação: (E13') "Morreram pessoas, mas não inocentes". Outra (E13") no sentido hipotético, que sugere um limite de "saber" e de "conhecimento": “(sei que, pelo menos inocente) não morreu ninguém".

Mas o mais provável, dado o contexto de enunciação, é que essa fala deixa transparecer que houve mortes, de pessoas, de não-inocentes. A inocência é um índice demasiado abstrato para indicar quem morreu. Mas as mortes nas favelas sempre foram legitimadas pela FD da guerra, em que há inimigos a serem mortos.

O comparativo com o passado para produzir o novo aparece como descrição das torturas e crimes que o tráfico cometia na favela. Isso vai ser descrito em E11, E12, E14 e E19. A descrição das cenas de pauladas, gritos, torturas e agressões servem para ampliar o sentido de violência em que viviam os moradores. Ela cria o efeito de que realmente a

\section{Dossiê Espaço Urbano e Imaginação Cultural - https://revistaecopos.eco.ufrj.br/ \\ ISSN 2175-8689 - v. 22, n. 3, 2019 \\ DOI: 10.29146/eco-pos.v22i3.27415}


favela era o espaço único e exclusivo dessas práticas. Além de reforçar o medo no qual os moradores viviam. 0 aparecimento disso só é possível porque é preciso enfraquecer o "inimigo", deslegitimar seu domínio para que se o Estado se estabeleça. O que $O$ Globo está dizendo é que a pacificação trouxe mudanças na favela

Em E17, é a ponte entre o passado de terror e o futuro de leveza e alegria que se instala. A moradora diz que não olhava na cara dos traficantes e que evitava sair de casa por medo. Ela agora diz que está bem melhor e que sai mais de casa. As falas dos moradores reforçam o sentido de mudança que atravessa $O$ Globo. Elas servem para atestar que a favela, depois da ocupação, realmente tornou-se outra.

O jornal destaca a mudança de ares da favela, o ar como metáfora do ambiente, leve e livre de opressão. E15, E18 e E19 nos mostram essa mudança. E16 é fundamental, onde se diz: "parece que estou passando por uma libertação". Talvez ele seja a chave para entendermos a FD que está emergindo na cobertura de $O$ Globo.

A FD da guerra permitiu a produção de um enunciado como "Guerra do Rio" que serviu de sobretítulo para parte das matérias de ocupação. Contudo, esse enunciado se desloca para "Favela Livre" na cobertura dos processos de pacificação. Esses dois são indícios da passagem de uma FD para outra. A libertação é o efeito de sentido que vem se estabelecendo. Ela embasa, por exemplo, a palavra "pacificação", agora positivamente, e não como contraste a uma realidade anterior. 0 vocábulo, portanto, anuncia-se como um ponto de deriva, um ponto de intersecção entre duas formações que se relacionam pelo avesso. Pode-se dizer que começa a emergir uma FD. Aqui vamos chamá-la provisoriamente de $F D$ da libertação, já que ela é ainda uma realidade instável, e que não sabemos se produzirá identificações, percepções subjetivas, novos sujeitos.

Mas, apesar de instável, ela permite enxergar o cotidiano da favela. Obviamente, conforme dissemos, narrar o cotidiano da favela passa a ser uma luta política, já que somente afetado por essa FD $O$ Globo consegue sair dos sentidos de Guerra, apesar de sempre rememorá-los para criar a evidência da mudança.

E20 - A retomada das favelas dos complexos do Alemão e da Penha já começou a surtir efeitos nos índices de criminalidade da Zona Norte. Os chamados crimes de rua (assalto a pedestres e roubos de celulares e em ônibus) diminuíram 41,3\% entre os dias 26 de novembro e 9 de dezembro, em comparação ao mesmo período do ano passado.

Dossiê Espaço Urbano e Imaginação Cultural - https://revistaecopos.eco.ufrj.br/ 
E21 - O bom efeito colateral: Ocupação nos complexos da Penha e do Alemão derruba índices de crimes na Zona Norte.

E22 - "As imagens mostradas pela televisão daquele grupo de bandidos fugindo da Vila Cruzeiro para o Alemão contêm uma série de pessoas que eu chamo traficantes de ocasião. Muitos deles, após a ocupação, abandonaram o crime, perceberam que não vale a pena. E agora os que se consideravam chefes, como Pezão e FB, perderam os homens a quem eles delegavam operações, os que saíam às ruas para cometer crimes".

A produção da FD da libertação precisa buscar evidências de mudança, e é nesse sentido que esses enunciados, retirados da matéria "O bom efeito colateral" ( $O$ Globo, p. 18, 11/12/2010), funcionam. Eles servem para atestar que a favela está mudando e, por reflexo, o seu entorno e a cidade. E20 e E21 trazem dados que mostram a queda nos números de assaltos e roubos de carros. Reforçam o fato de que agora a favela recebeu “ordem", está controlada pelo Estado, e de que era antes, de fato, o lugar do crime e da violência na cidade.

E22 é um pouco mais complexa, mas mostra uma realidade que era invisível na interpretação da cidade e da favela sob a FD da guerra. Enquanto nas descrições baseadas nos conflitos o destino de quem se envolvia com o tráfico já estava traçado - ou a morte, ou a cadeia -, agora isso é relativizado na fala do policial, que mostra não haver ali pessoas que se envolveram com o crime por ocasião, mas que agora voltarão para seus trabalhos.

Dessa forma, a FD da libertação embola um pouco as verdades do imaginário sobre a favela e seus sujeitos. Os sentidos estão em disputa mais do que nunca nesse momento, logo não se julga ou se cobra a prisão desses que estiveram envolvidos. A estes é dado o direito de recomeçarem suas vidas.

\section{Considerações finais}

Não houve mudanças substanciais na vida dos moradores do Alemão. 0 Complexo continuaria com suas deficiências materiais, mas com vida típica, com sua cultura, seus modos de vivências e experimentações cotidianas. Um aspecto do Complexo parecia superado: a luta entre facções teria entrado em estado de espera. Ou controlada de vez. 0 
tráfico, evidentemente, se manteria. Talvez não armado, ou não tão armado. 0 que queremos dizer é que um aspecto, entre tantos, não é o suficiente para estabelecer uma realidade total da favela. 0 discurso d'O Globo, no entanto, mostra uma mudança tão significativa, que parece querer reencontrar as favelas romantizadas pela literatura e pela canção popular.

Essa guinada discursiva, esse ponto de dobra, é o que nos faz afirmar que, pelo menos em parte, anunciou-se um deslocamento discursivo, com abertura de sentidos, e prenúncio de uma outra formação discursiva.

Mas a abertura para novas discursividades não anula a memória já estabilizada de determinadas formações discursivas. Esses fenômenos não são, de forma alguma, uma descoberta desta pesquisa; eles estão na base de toda a teoria do discurso. Na verdade, o aparecimento do novo está condicionado à existência do velho. Nossa pesquisa é apenas uma parte na percepção desse processo.

Mencionamos essa questão para mostrar o quanto a vontade de determinar o sentido dos lugares e dos acontecimentos não é suficiente para produzi-lo. Ainda que $O$ Globo queira apresentar uma favela livre do tráfico, a memória, o inconsciente e a ideologia se fazem presentes e os dizeres falham.

Há em toda a narrativa d'O Globo uma vontade de produzir os sentidos de "Favela Livre"; a FD da libertação talvez manifeste mais o desejo do jornal e do "Poder Público" do que a realidade do imaginário e o real da favela. Mas a memória da favela na cidade como um mundo à parte se mantém, continua a produzir sentidos.

A memória do discurso, dos dizeres sobre a fissura entre "favela" e cidade, "morro" e "asfalto" permanece à espreita. Ou seja, a favela ainda é um espaço diferente, ainda que a pacificação quisesse inseri-la na ordem comum da cidade.

\section{Referências bibliográficas}

CERTEAU, M. A invenção do cotidiano, vol. 1: artes de fazer. Petrópolis-RJ. Vozes, 1990.

FOUCAULT, Michel. Microfísica do Poder. São Paulo-SP, Editora Graal, 2008.

GUIMARÃES, Eduardo. Semântica do Acontecimento. Um Estudo Enunciativo da Designação. Campinas- SP, Editora Pontes. 2002 
MASSEY, Doreen. Pelo Espaço: uma nova política da espacialidade. Rio de Janeiro - RJ. Bertrand Brasil, 2005.

MENDONÇA, Kléber. O Imperador da Chatuba: o jogador Adriano entre a delinquência e o discurso de "pacificação" da cidade. Trabalho apresentado no GP Geografias da Comunicação do X Encontro dos Grupos de Pesquisa em Comunicação, evento componente do XXXIII Congresso Brasileiro de Ciências da Comunicação. Caxias do Sul - RS. 2010

ORLANDI, Eni P. Cidade dos Sentidos. Campinas - SP. Editora Pontes, 2004.

Editora Pontes, 2007.

Interpretação: Autoria, leitura e efeitos do trabalho simbólico. Campinas - SP.

. Análise de Discurso. Princípios e Procedimentos. Campinas -SP, Editora Pontes.

2005.

. As Formas do Silêncio. Campinas - SP. Editora Unicamp,2009. SODRÉ, Muniz. A Narração do Fato. Petrópolis - RJ. Editora Vozes, 2009. 